\title{
Parametric modelling based approach for efficient quantity takeoff of NATM-Tunnels
}

\author{
Daegu Cho ${ }^{1}$, Nam-Seok Cho ${ }^{1}$, Hunhee Cho ${ }^{{ }^{*}}$, and Kyung-In Kang ${ }^{1}$ \\ ${ }^{1}$ School of Civil, Environmental and Architectural Engineering, Korea University, Seoul, \\ Korea \\ * Corresponding author (hhcho@korea.ac.kr)
}

\begin{abstract}
Purpose As every construction project is quite different according to the type of construction, 3D-representations on design, estimation, construction, and management also need to be different. While the 3D-approach has been widely applied to building projects, it has rarely been tested on large construction projects such as tunnels, mass transit systems, dams, highways, etc. Meanwhile, characteristics of NATM (New Austrian Tunnelling method) tunnel projectsincluding long-linear-simple shapes, cyclic-repetitive operations, and relatively small numbers of objects-are compatible with parametric modeling that can be supported by BIM-applications ${ }^{5}$. The purpose of this paper is to propose an efficient approach for quantity takeoff of NATM-tunnels, using parametric modeling. Method NATM-tunnel characteristics are described that should be applied to the 3D-modeling and technical requirements for parametric modeling functions toward obtaining efficient solutions. Results \& Discussion Results from a pilot project indicate that standardization on tunnel libraries, parameters, levels of detail, and parametric relationships can dramatically improve the efficiency of quantity takeoffs.
\end{abstract}

Keywords: information technology, BIM, parametric modeling, NATM tunnel

\section{INTRODUCTION}

Building information modeling (BIM) can be considered an epochal revolution in the way to design, build, share, and communicate. While meaningful BIM can be accomplished by collaborative effort of project teams from the very beginning of construction projects, current BIM environment is immature to fully support diverse demands from various project teams. BIM technologies not only have promised new opportunities to improve process in the construction industry, but have generated new challenge areas.

One of new challenge areas is to develop a welldefined library that provides automatic design ability and product information across project participants throughout the life cycle of a facility, at the aspect that library development is the most fundamental step in the BIM process. BIM utilizes a cutting edge digital technology to establish a computable representation of all the physical and functional characteristics of a facility throughout the life cycle of a facility ${ }^{4}$. Therefore, a BIM library as not a simple graphic representation but the most fundamental unit to compose modeling needs to involve physical and functional characteristics reflecting professional knowledge from diverse project participants. According to the building SMART Korea (bSK) report, $66 \%$ of architectural engineers describes the lack of available library and its contents as the major obstacle of BIM adoption ${ }^{1}$.

An open library system can save considerable time, effort, and cost required in the modeling process.
Although free of charge online libraries are recently available through various channels, they are little useful in real practice because they might have (1) low quality or out of date data, (2) different standards, codes, level of detail or format, (3) inappropriate parametric rule, metadata, and data structure, or (4) difficulties in modification. On the other hand, a small piece of libraries requires additional effort and professional knowledge to apply the libraries one by one into modeling. Therefore a more systematic approach should be prepared in developing BIM libraries in order to facilitate BIM.

This paper proposes a new concept of development approach of BIM libraries, a holistic system library that integrates a small piece of libraries into a batch of libraries with identical parametric behaviors and product data. The new concept of development approach is useful for a prefabricated or modularized product (e.g., precast concrete, steel stair, etc.), a manufactured product (e.g., air conditioner, boiler, etc.), and a standard type of construction (e.g., standard masonry wall system, standard pavement system, etc.). This paper seeks to confirm the hypothesis that a systematic approach to develop BIM library provides efficient way to design, build, share, and communicate in the BIM process.

\section{SCOPE \& METHODOLOGY}

The primary purpose of this paper is to find an efficient way to develop a systemic BIM library, focusing on the standard type of NATM tunnel construction. To coping with the purpose, extensive literature re- 
views on recent technologies and trends of BIM library development, definition of BIM library, parametric modeling, NATM tunneling methods, and software applications have been implemented. Seven standard types of excavation works from a NATM tunnel project are developed as a holistic system library using Autodesk Revit and Digital Project. Lessons learned from the library modeling process and expected advantages of the proposed approach are summarized in the conclusions.

\section{LITERATURE REVIEWS}

\section{BIM Library and Interoperability}

Due to the increasing complexity of buildings and design processes, a systemized method of information exchange in the construction industry is increasingly important. At the aspect of microscopic level, a construction project is an assembly of a great number of objects. Meanwhile, BIM is usually called an intelligent object modeling providing automatic design ability and meaningful product information. In other words, a construction project is represented by objects and their relationships. The objects are represented as libraries in BIM. Therefore, libraries can be referred as the most basic element that represents the way to design, build, interoperate, share, and communicate in the BIM.

Based on the motivation, various public and private associations such as The National BIM Library(NBL), ARCAT, RevitCity, SMARTBIM, Autodesk Seek, etc. provide free of charge online libraries and contents, the guidelines for development, and standard classifications. They provide various types of libraries using a specific domain of software application such as Revit, Bentley, ArchiCAD, Digital Project etc. Figure 1 illustrates an example of public libraries provided by NBL.

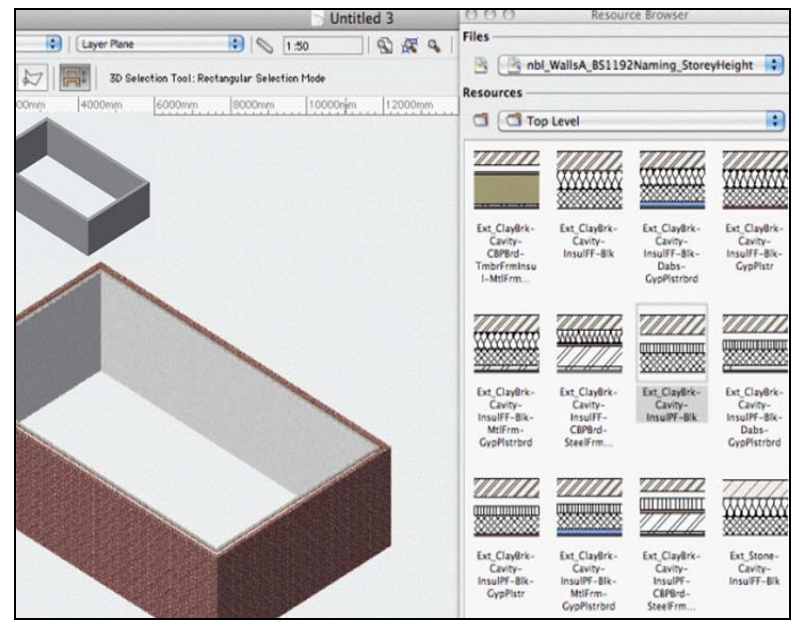

Fig.1. Screenshot shows a very simple example of concept walls being developed into detailed walls using predefined libraries (NBL, 2012)
However, these libraries are little available between different software applications in the real practice because respective applications have different (1) definitions of their basic objects, (2) capabilities representing geometry information, (3) parametric rules, and (4) property classification. The interoperability problems are frequently generated even in a single software application, according to different (1) design intend, (2) level of detail, (3) software skill, (4) standard compliance and so on. Considering BIM standards are not yet well defined and widely adopted, developing a standard library must be quite difficult.

\section{LIBRARY DEVELOPMENT}

Various BIM software applications provide a growing set of object-oriented parametric approaches with a predefined set of object families embedded object instances and parametric rules. These tools provide much more complex structures of object families and relations among them. In the library development process, a developer needs to decide (1) geometry representations (extrusion, blend, revolve, sweep, and swept blend), (2) relations (assigns, decomposes, associates, define, connects, etc.) among objects, (3) properties (material, performance, contextual properties) of objects, and (4) metadata and data structure for information management.

Parametric modeling equipped in most commercial BIM software applications is a useful tool to develop a library. Parametric modeling, as opposed to explicit modeling, has been early used to design and engineer products in diverse manufacturing industries. Parametric modeling involves the definitions of objects and relationships among objects. These definitions and relationships enable a developer to explore a range of design options using underlying parameters.

The parametric modeling capability proposes easy modeling process in generating intelligent objects without complex programming, in coordinating automatic changes, and in maintaining consistency. In parametric design, instead of designing an instance of a building element, an object is defined using parameters involving distance, angels, and rules like attached to, parallel to, and distance from. These relations allow each instance of an element class to vary according to its own parameter settings and contextual relations ${ }^{3}$. Well-defined parametric rules enhance design and engineering productivity, allowing low-level changes to update automatically.

However, frequently the predefined approaches make it difficult to define a new rule, because their pre-defined approaches are customized for building families that do not allow some special cases. In other words, the predefined approaches are complete only for the most standard types of a building construction such as column, beam, slab, window, 
door, etc. The parametric modeling based approach involves the following limitations;

(1) Inflexible predefined rule sets

(2) Limited objects and extensibility

(3) Interoperability issues

(4) Professional knowledge and skill

(5) Considerable effort, time, and cost

\section{NATM Tunnel}

The New Austrian Tunneling Method (NATM), also commonly referred to as the Sequential Excavation Method (SEM) uses the inherent strength in the rock mass to support the roof during excavation. Because this self-supporting capability achieves economy, flexibility in uncovered ground conditions, and dynamic design variability, NATM is widely applied for underground structures. NATM tunnels are largely dependent upon round length, types of support, and ground conditions such as shear strength, deformation, and groundwater level.

Excavation methods and supporting patterns are predefined using "types" in the planning phase. As ground conditions deteriorate, the type number increases, the number of supporting processes (such as rock bolts, steel plates, and forepoling) increases, and the length of excavation per cycle decreases from 3.5 meter to 1.0 meter.

Seven types (e.g., Type-I, Type-II) are used as a standard tunnel in the Korean construction industry. The standard types provide a common platform for project participants to communicate in the field. Cross section of Standard Type -1 representing detailed dimensions and characteristics of tunnel shape is illustrated in Figure 2.

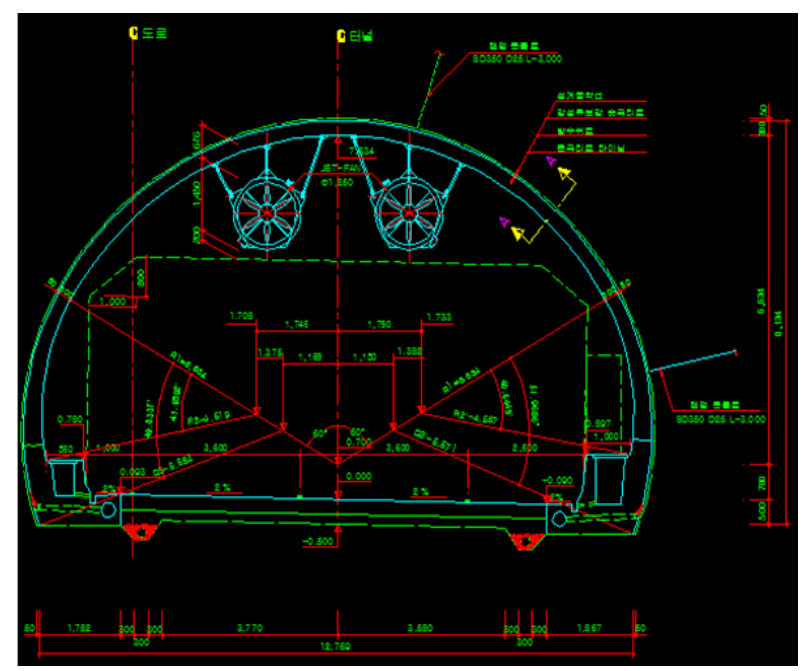

Fig.2. Cross section of Standard Type-I representing detailed dimensions and shape

Unlike a building project having vertically repetitive structure and very large numbers of elements, tunnel projects are characterized by (1) relatively small numbers of elements, (2) horizontally long and linear shape and (3) availability to other Standard Types.
Representative elements for tunnel structure frame in BIM are excavation lining, rockbolt, shotcrete, concrete lining, waterproof membrane, drainage channel, wall tile, perforated drainpipe, utility conduit cover, and concrete pavement, illustrated in Figure 3.

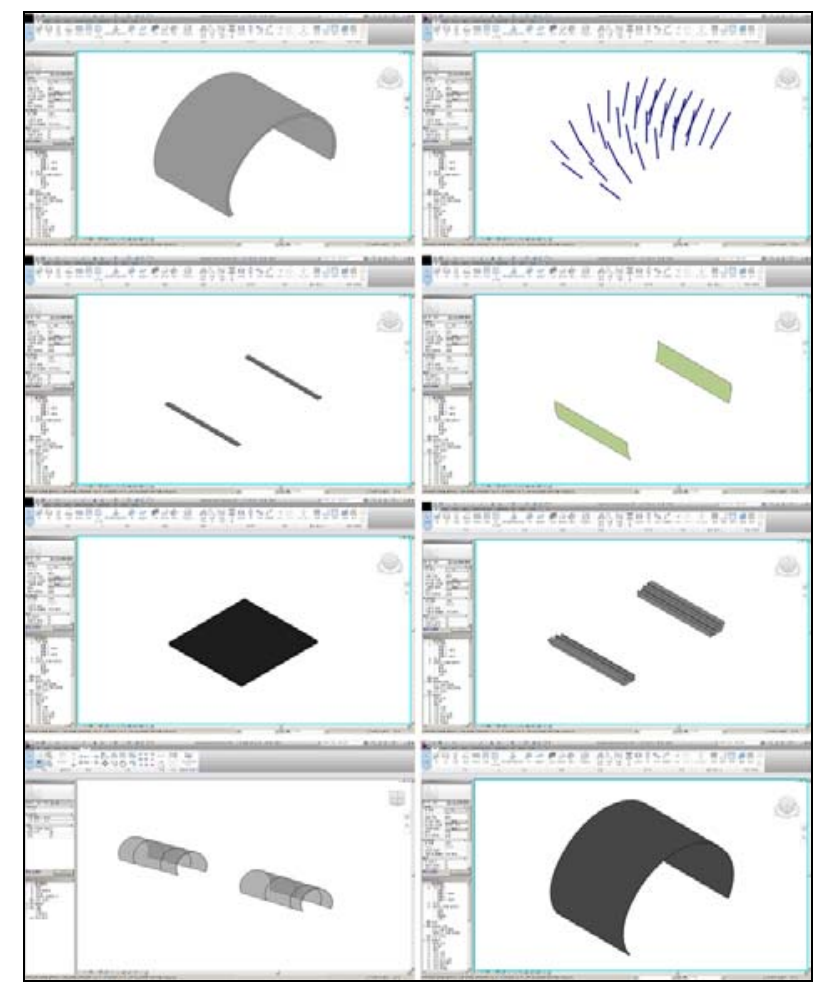

Fig.3. Libraries development for a tunnel structure

The different characteristics of the large scale of project might positively impact on the BIM approach. On the other hand, unlike a building project, these libraries are not embedded in a software package such as system families or component families that can be created and customized in an external library. For example, "concrete lining library" can be generated using a beam or wall library in the component families, which has quite different attributes. Although the individual library can be developed, it is rarely useful to represent the combined structure of a tunnel project.

Therefore, a holistic approach is required to represent overall structure of tunnel projects. Parametric modeling capability can be available to define individual object's behavior and relationships among objects. This paper proposes a holistic BIM library concept to overcome the limitations from a commercial software application and the limitations from parametric modeling.

\section{Holistic System Library}

A BIM library might combine geometry information such as 2D, details, and 3D drawings with property information including dimensions, positions, standard codes, materials, etc. and product information including specifications, manufacturer, price and procurement, codes, and schedule. In this paper, a 
holistic system library is defined as a systematic approach to integrate geometry, property, and product information into a single BIM library. The concept of a holistic system library is designed for the efficient approach to BIM throughout the project life cycle. Figure 4 illustrates an example of a holistic system library involving geometry, property, and production information.

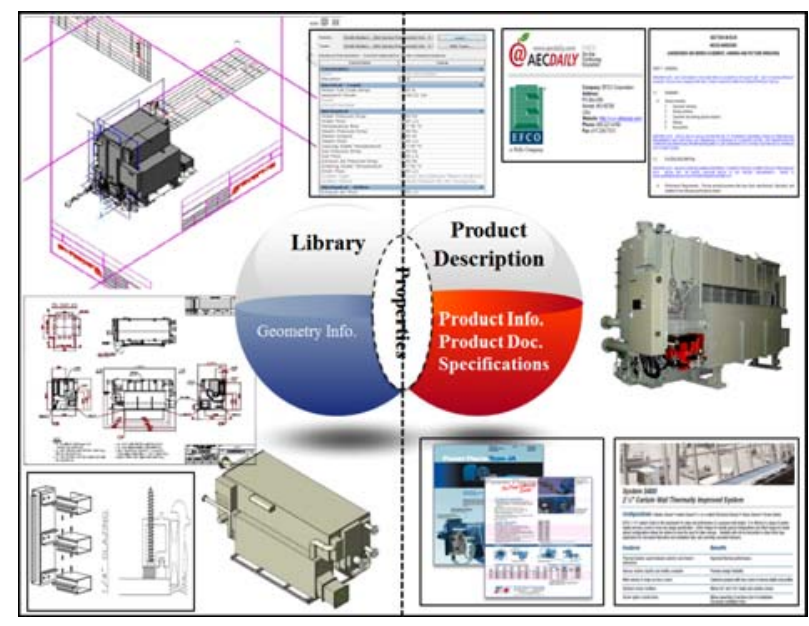

Fig.4. An example of a holistic BIM library and its contents ${ }^{2}$

Development of a holistic system library enables project participants not only to access consistent and high-quality information, but also to improve productivity and efficiency in the design and communication process. For example, information from a holistic system library can be exported and used in various field applications such as quality assurance using specifications, bills of material using quantity takeoff, detailed drawing generation using geometry information, and so on.

\section{System Applications Pilot Project}

Development of a holistic system library is tested using a pilot project. The Samtan 1 tunnel is the longest tunnel (2,645 meter in the Samchuk direction and 2,619 meter in the Jeachen direction) in the Samchuk-Jeachen road construction in South Korea. The NATM tunneling method and seven standard types were employed in the project. Total duration was 48 months for the two-portal tunnels with twolane roads.

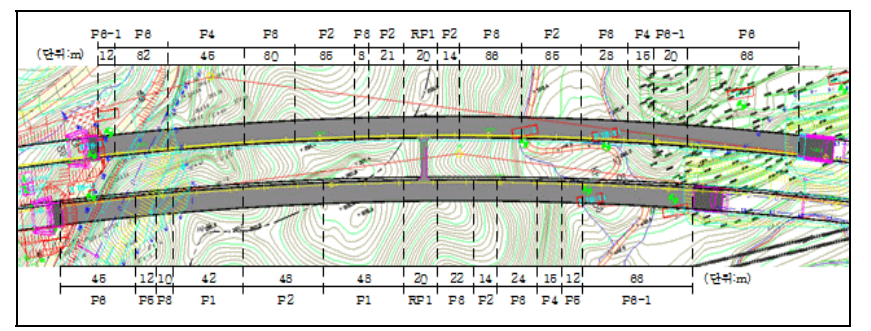

Fig.5. Prototypical longitudinal profile of pilot project, Samtan 1 Tunnel
Autodesk Revit Architecture 2012 and Digital Project are used to develop a holistic system library and to distinguish differences in major functional and performance capabilities, focusing on easy of developing custom parametric objects.

\section{Autodesk ReVit Based Approach}

Autodesk Revit Architecture is the best known and current market leader of the use of BIM. An example of the holistic system library using Revit is illustrated in Figure 6. Individual libraries illustrated in Figure 3 are combined into a single Standard Type library. The holistic system library automatically generates geometry, property, and product information according to the predefined parametric rules. A reference line, center line of a tunnel having traverse and vertical slope is used to extend the holistic system library as the length of the applied Type. For example, if Type 1 is supposed to implement in the first 12 meter, a user extends the Type 1 system library into 12 meter in the reference line. Consequently, relevant information is automatically generated, which includes properties, quantities (total length, area, volume), cost and schedule data, etc. Figure 7 illustrates the process how the holistic system library implements.

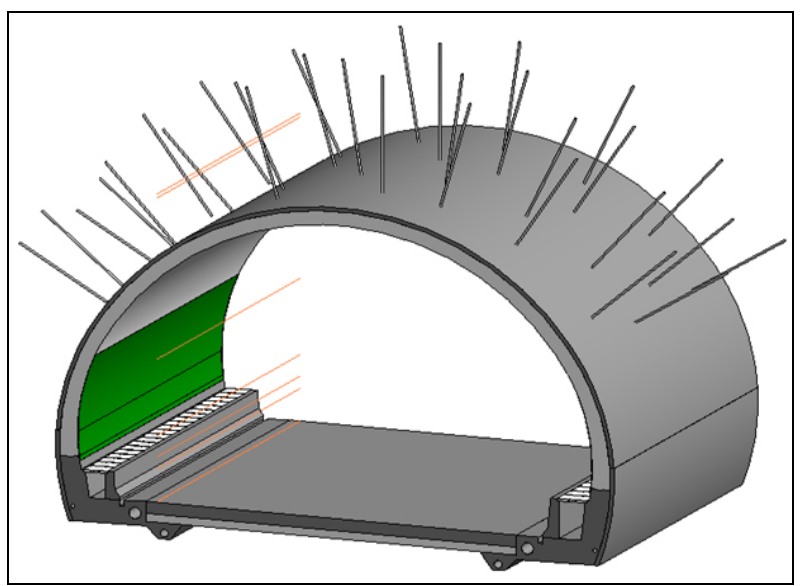

Fig.6. An example of holistic system library of Standard Type 1

Well-designed functionality, user-friendly interface, easily available libraries, presentation of complex shapes, and modeling methods, extensibility to Excel format and protocols are identified as its strengths.

On the other hand, lot of trial and error for more than four months has involved in developing geometric shape and defining parametric rules due to the lack of (1) field experience, (2) understanding quantity takeoff, and (3) capability on supporting parametric modeling. Because libraries are not defined in system families or component families, a developer needs to define an object behaviors and attributes and drawing template one by one.

A structural frame is used for developing the tunnel structures because a tunnel project is composed of 
repetitive operations and represented by a horizontally long linear structure. Automatic coordination parametric rule between objects built in the structure frame generates predefined tapered sections. The automatic coordination rule causes $0.5 \%$ of error in calculating quantity. Due to inflexible rule sets provided by Revit, it has remained as the unsolved limitation hindering the reliability of accurate quantity takeoffs. Limited object sets and relatively large scalability are identified as limitations of Revit based approach to development of a holistic system library.

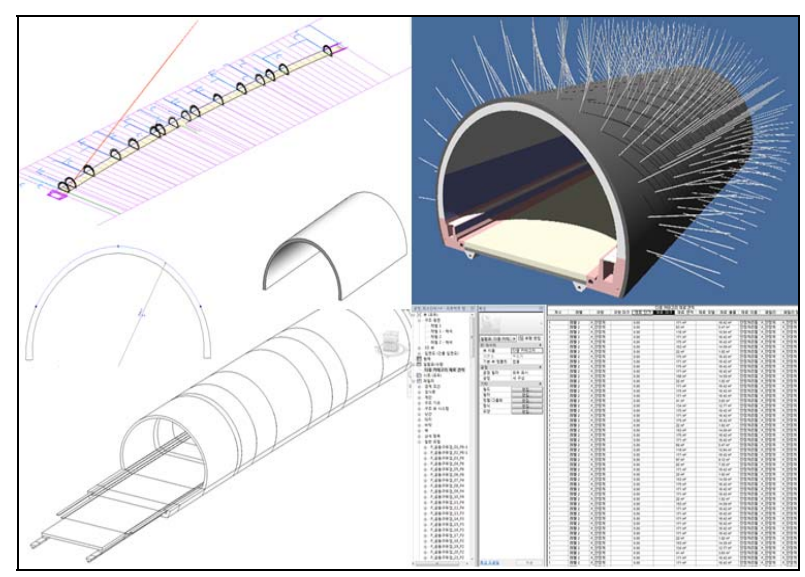

Fig.7. Implementation of a holistic system library representing a reference line and information generation according to predefined parametric modeling in Revit

\section{Digital Project Based Approach}

Digital project is the world's most widely used parametric modeling platform in various industries ${ }^{3}$. It is appropriate for a large project required elaborate custom parametric objects. It support visual basic for application (VBA) scripting and a strong application programing interface (API) which are useful for developing add-on programming and facilitating integration of specification for cost estimating ${ }^{3}$. On the contrary to Revit, a developer arbitrarily defines diverse parametric rules and models any type of surface using points, lines and faces. Developing process of a holistic system library involves generating testing lines and points, defining input elements for the lines, developing object section and volume, defining parametric rules a developer represents, and testing and modifying. Trial and error processes are also required, but Digital Project can reduce considerable time in the processes comparing with Revit. Error can be significantly reduced by the detailed definitions of input elements and by VBA and API tools. Systematic data structure on the holistic system library should be managed to reduce overall scalability. Complex user interface, high initial cost, and limited open library are weaknesses of the software application. Figure 8 illustrates Digital Project based approach to the holistic system library.

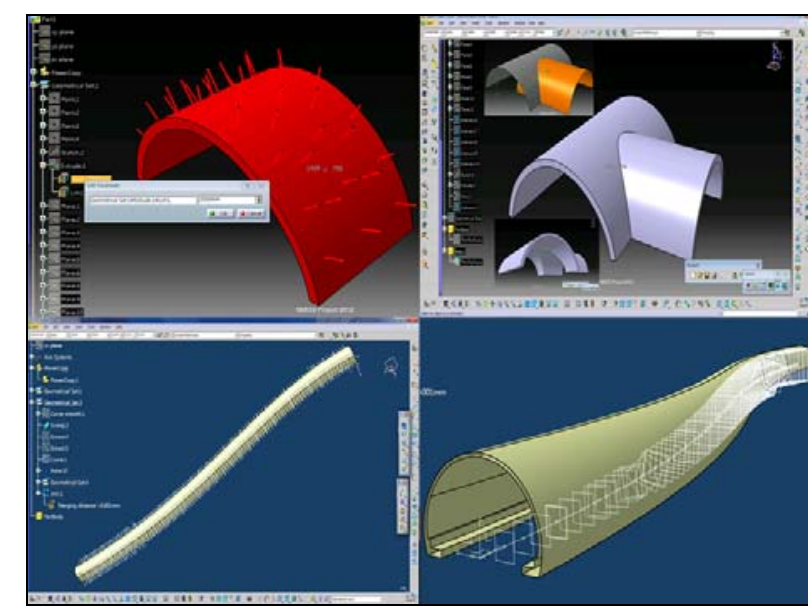

Fig.8. Implementation of a holistic system library using strong parametric modeling ability in Digital Project

\section{Conclusions}

As construction projects become more complicated, increasingly specialized, and large in scale, collaboration between project participants is getting more and more emphasized over last few years. The collaboration tools for participants might vary, but traditional drawings and specifications play an important role. BIM technologies have introduced both new challenges and opportunities in the construction industry. While meaningful BIM can be accomplished by collaborative effort of project teams from the very beginning of construction projects, current BIM environment is immature to fully support diverse demands from various project teams.

Development of BIM library and contents has been regarded as one of the most basic requirement for the wider adoption of BIM. Based on the literature reviews and applications to commercial software, this paper proposes a holistic system library concept in developing BIM library. Many trials and errors and more than four months of development process have been implemented in order to develop the holistic system library appropriate to standard tunneling works. Public users can save considerable time and effort and in addition have rich product information through opening the holistic system library in online. The following benefits can be achieved by the approach of holistic system libraries;

(1) Reducing interoperability limitations in a single software application and scalability limitations at a high level of detail

(2) Saving considerable time, effort, and money required for develop a library

(3) Suggesting qualified and consistent standard data across the construction industry

(4) Sharing and maintaining information with a highly effective way

(5) Allowing project teams to facilitate BIM technologies in the various construction areas 
(6) Promoting collaborative environment throughout the project life cycle with an effect and efficient manner.

More application areas such as standard types of road or bridge construction and quantitative measurement on the benefits remain in the future extension of the research.

\section{Acknowledgement}

This study is part of a research project sponsored by the Korea Institute of Construction and Transportation Technology Evaluation and Planning (KICTEP) under Grant No. 09CCTI-B052843-01. The support is gratefully acknowledged.

\section{References}

1. building SMART Korea (bSK), "Survey on BIM Adoption in Korean Construction Industry", The BIM, Spring, 2009.

2. Cho, D.G., Ko, Y.W., and Kim, I., "Developing BIM Library and Contents Exchange System for Collaboration Work Environment", 2010 Fall Proceedings of the Architectural Institute of Korea, Chungju, Korea, 2010.

3. Eastman, C., Teicholz, P., Sacks, R., and Liston, K. BIM Handbook: A Guide to Building Information Modeling for Owners, Managers, Designers, Engineers and Contractors, John Wiley and Sons, $1^{\text {st }}$ ed. NY, 2008.

4. Gallaher, M., O'Connor, A., Dettbar, J., and Gilday, L., "Cost Analysis of Inadequate Interoperability in the U.S. Capital Facilities Industry", NIST GCR 04867, U.S. Department of Commerce Technology Administration, National Institute of Standards and Technology, 2006.

5. Obergrieber, M., Euriger, T., Borrmann, A., and Rank, E., "Integration of Geotechnical Design and Analysis Processes Using a Parametric and 3D-Model Based Approach", Proceedings of the 2011 ASCE International Workshop on Computing in Civil Engineering, Miami, Florida, U.S., 2011. 